\title{
Use of the Arabic Version of Oral Health Impact Profile-14 to Evaluate the Impact of Periodontal Disease on Oral Health-related Quality of Life among Saudi Population
}

\author{
Khalid Y Hakami ${ }^{1}$, Navin A Ingle ${ }^{2}$, Mansour K Assery ${ }^{3}$, Jamal A Alsanea ${ }^{4}$
}

\begin{abstract}
Introduction: Most commonly, the quality of life (QoL) measure used for evaluating the influence of oral diseases on individuals is Oral Health Impact Profile-14 (OHIP-14). Knowledge regarding particular illness in a population will help us to implement a new policy or modify the existing health policies and also help us to plan and deliver better preventive and treatment to the population.

Aim: The purpose of the present research was to assess the impact of periodontal diseases in Saudi population.

Materials and methods: A hospital-based cross-sectional study was carried out among with 400 adult subjects using the OHIP-14 structured questionnaire, which is an effective yardstick for oral conditions and their purported management need. Oral examinations were performed by single dental professionals. Data were subjected to the statistical analysis with a significance level set at $p<0.05$.

Results: This study comprised 400 adults ( 216 men and 184 women) with a mean \pm SD OHIP-14 score of $13.92 \pm 8.21$. Among the seven domains, physical disability, psychological disability, and handicap subscales of OHIP-14 showed a significant difference in periodontal severity $(p=0.01)$. The average psychological disability subscale mean scores were significantly higher among mild periodontitis as compared to its moderate and severe counterparts. Whereas the handicap subscale mean scores were significantly higher for subjects with moderate periodontitis as compared to chronic gingivitis subjects $(p=0.01)$.

Conclusion: The periodontal disease definitely has negative influence on QoL of the subjects among the Saudi population.

Keywords: Oral health impact profile-14, Periodontal disease, Quality of life.

Journal of Oral Health and Community Dentistry (2020): 10.5005/jp-journals-10062-0068
\end{abstract}

\section{INTRODUCTION}

An extensive variety of clinical features were publicized by periodontal diseases, which have a definite influence on quality of life (QoL) measure. ${ }^{1,2}$ Oral health-related quality of life (OHRQoL), which indicates easiness while sleeping, speaking, smiling, socializing, self-esteem, and gratification, is a multidimensional construct. ${ }^{1,3}$

The measuring tool should embrace context-, culture-, and environment-specific qualities. ${ }^{4-6}$ This has shaped the requirement to cross-culturally acclimatize these measures specifically in the global village where association in medical and dental research is greatly motivated. ${ }^{4,5,7}$ Many studies reveal that periodontal illnesses have a damaging impact on the QoL of affected subjects. ${ }^{8-14}$ Reports show that among the subjects with severe periodontitis, the negative effects had a greater impact than healthy individuals. Along with the capability to eat, express, and socially interact, periodontitis can affect relationships and day-to-day functions. ${ }^{8-13}$ It can also alter the subjects' smiling pattern and smile-related QoL. ${ }^{15}$ In order to certify the preparation and assessment of periodontal care and management appropriately, a healthier understanding of the impacts of periodontal illness and its management along with the association between oral health and QoL, patients' needs, and concerns is essential. ${ }^{16,17}$ Subjects show positive behavior on general health and QoL when they have comprehensive knowledge about oral illnesses on teeth and adjacent tissues. ${ }^{1,18}$

Though the Oral health impact profile-14 (OHIP-14), which was first established in Australia' ${ }^{19}$ to quantify OHRQoL in relation to various oral diseases, has been authenticated in other regional
${ }^{1,2,4}$ Department of Dental Public Health, Riyadh Elm University, Riyadh, Kingdom of Saudi Arabia

${ }^{3}$ Department of Prosthodontics, Riyadh Elm University, Riyadh, Kingdom of Saudi Arabia

Corresponding Author: Khalid Y Hakami, Department of Dental Public Health, Riyadh Elm University, Riyadh, Kingdom of Saudi Arabia, Phone: +966 508633249, e-mail: kkkk1409@hotmail.com

How to cite this article: Hakami KY, Ingle NA, Assery MK, et al. Use of the Arabic Version of Oral Health Impact Profile-14 to Evaluate the Impact of Periodontal Disease on Oral Health-related Quality of Life among Saudi Population. J Oral Health Comm Dent 2020;14(1):27-31. Source of support: Nil

Conflict of interest: None

languages such as the United States, ${ }^{20}$ Scotland, ${ }^{21}$ and Canada, ${ }^{22,23}$ very meagre research aimed to measure the impact of oral diseases on QoL among Saudi population. Hence, the current research aimed to assess impact of periodontal diseases on QoL among Saudi population.

\section{Materials and Methods}

The cross-sectional research involved subjects who were referred to Riyadh Elm University (REU). A total of 400 individuals, aged 18 years or older with minimum of 15 teeth, were selected through systematic random sampling over the 6-month period from July 2018 to December 2018. Subjects were selected randomly from

(c) The Author(s). 2020 Open Access This article is distributed under the terms of the Creative Commons Attribution 4.0 International License (https://creativecommons. org/licenses/by-nc/4.0/), which permits unrestricted use, distribution, and non-commercial reproduction in any medium, provided you give appropriate credit to the original author(s) and the source, provide a link to the Creative Commons license, and indicate if changes were made. The Creative Commons Public Domain Dedication waiver (http://creativecommons.org/publicdomain/zero/1.0/) applies to the data made available in this article, unless otherwise stated. 
the REU outpatient department who fulfilled the selection criteria using convenience sampling as this method is quick, inexpensive, and convenient and the researcher can select the sample elements according to their convenient accessibility and proximity utilizing the inclusion and exclusion criteria.

Saudi subjects with minimum 15 intact teeth, no history of periodontal treatment for last 6 months, and $>18$ years of age were included in the present research. The criteria for exclusion were the following: any person who refused to participate or to sign the consent, systemic diseases or currently on medication which affect the periodontal tissues, history of alcoholism, pregnant or lactating mothers, patients with a mental or psychological disorder, and any subjects who will not match the inclusion criteria. Using the G-power sample size calculator, 95\% power, the required sample size for the present research was 386 . The data were collected from 432 individuals. Thirty-two incomplete questionnaire was excluded from the analysis and we used 400 samples for final analysis.

\section{Data Collection}

After the approval of this study by REU, a written consent was attained from all the participants. With the help of an organized questionnaire, individual interviews were held in order to accumulate the baseline statistics from every subject. The questionnaire involved relevant characteristics such as sex, age, marital status, education, total family income, self-reported history of the medical problem, the frequency of brushing, the frequency of dental visit, and periodontal treatments in last 6 months.

\section{Instrument}

To calculate the influence of periodontal diseases on QoL, OHIP-14 was used. The OHIP-14, which has 14 scales to embrace the seven dimensions to measure the $\mathrm{QoL}$, is a self-administered questionnaire. The seven dimensions are physical functioning, physical pain, physiological disability, physical disability, psychological disability, social disability and handicap. Every dimension was measured using two questions. The participants were asked to report the frequency of adverse experiences in relation to these dimensions within the last 12 months. Using the five-point Likert scale of 0 to 4 , each scale was expressed as: never; hardly ever; occasionally; fairly often; very often. All the responses to the items were collected. If the responses were fairly often or very often ( $\geq 3$ on the five-point Likert scale), the response was considered as present. The percentage of individual answers being fairly often or very often on every item of OHIP-14 was measured. ${ }^{19}$ By summing all the scores, the entire OHIP-14 score was obtained and thus stretched from 0 to 56 points. 19,24 The original English version of the OHIP-14 questionnaire was translated. Two experienced bilingual English teachers from Kings Saud University who were fluent in English (and for whom Arabic was their native language) autonomously translated the questionnaire from English to Arabic. ${ }^{25}$ The resulting version was then translated back to English by a professional translator, who was blind to the original English questionnaire, to reduce the translational bias. The theoretical homogeneity between the English and back-translated versions of OHIP-14 was affirmed by an expert committee of three specialists in periodontics and public health. Pilot research with 30 subjects was tested with the Arabic version to evaluate the validity (and content) within the target population. The generality of the apparatus was verified by questioning about complications in understanding the items. All changes that were necessary to progress the fluency of the OHIP-14 and methodological modifications were performed during pilot testing.

\section{Psychometric Properties}

Psychometric properties, validity, and reliability of the Arabic description of the OHIP-14 were verified. A pilot study data of 40 subjects were subjected to test-retest reliability, item internal reliability, and item discriminant validity and scale validity. All these tests showed satisfactory results with acceptable Cronbach's a values $(\geq 0.70){ }^{26}$

\section{Clinical Examination}

A professionally registered dentist examined all the participants for the periodontal status. The plaque and gingival status of six index teeth was gauged using the Loe and Silness plaque ${ }^{27}$ and the Silness and Loe gingival index (GI) respectively; probing pocket depth (PPD) clinical attachment loss, and gingival recession (GR) were assessed at only three sites per tooth, the mid-buccal, mesiobuccal and distobuccal sites, as labeled in other epidemiological research. ${ }^{27,28}$ The six selected index teeth were the maxillary right first molar, the maxillary left central incisor, the maxillary left first premolar, the mandibular left first molar, the mandibular right central incisor, and the mandibular right first premolar. The total burden of periodontitis was assessed using the definition of the illness as developed by the Center for Disease Control-American Academy of Periodontology (CDC-AAP). ${ }^{29}$ The CDC-AAP case definition of periodontitis was based on events of PPD and clinical attachment level $(\mathrm{CAL})$ at interproximal sites; the degree of severity was also considered. ${ }^{29,30}$ Severe periodontitis was defined as having two or more interproximal sites with $\geq 6 \mathrm{~mm} C A L$ (not on the same tooth) and one or more interproximal site(s) with $\geq 5 \mathrm{~mm}$ PD. Moderate periodontitis was defined as two or more interproximal sites with $\geq 4 \mathrm{~mm}$ clinical CAL (not on the same tooth) or two or more interproximal sites with $\geq 5 \mathrm{~mm} P D$, also not on the same tooth. Mild periodontitis was defined as $\geq 2$ interproximal sites with $\geq 3 \mathrm{~mm} \mathrm{CAL}$ and $\geq 2$ interproximal sites with $\geq 4 \mathrm{~mm} P D$ (not on the same tooth) or one site with $P D \geq 5 \mathrm{~mm}$. Total periodontitis was the sum of severe, moderate, and mild periodontitis. The WHO criteria were used to measure decayed, missing, and filled teeth. ${ }^{31}$ Severity of chronic periodontitis was classified as mild (attachment loss of 1-2 mm), moderate (attachment loss of 3-4 mm), and severe (attachment loss of $5 \mathrm{~mm}$ or more). ${ }^{32}$ The clinical examinations were performed by a carefully trained clinical expert, 20 days before the commencement of the study. Intraexaminer reliability for the PPD and CAL scores was analyzed and weighed by double recordings in 40 subjects. A 7-day gap was placed between the repeat recordings after the first clinical examination. The intraexaminer reproducibility was 0.80 for mean PPD scores and 0.96 for mean CAL scores, indicating very good agreement.

\section{Statistical Analysis}

The MS Excel 2010 Statistical Package for Social Sciences (SPSS, version 20, Chicago, IL, USA) was used for data handling and data analysis. The descriptive statistics were defined using frequency distribution for discrete and mean and standard deviation ${ }^{33}$ for continuous variables. The Chi-square test was used for categorical variables. One way ANOVA for PI, GI, CAL and PDL scores and the multivariate analyzes was performed for different variables of 
OHIP-14 subscales among periodontal disease groups. A $p$ value less than or equal to 0.05 was considered statistically significant.

\section{Results}

\section{Participant Characteristics}

This study comprised 400 adults (216 men and 184 women) aged between 18 years and 60 years, with a mean of 28.7 (10.9) years. Table 1 shows relevant baseline characteristics of study population. Most of them were single and had completed their graduation.

\section{Oral Hygiene and Periodontal Status}

Of the 400 patients, $64 \%$ had chronic gingivitis, $22 \%$ had mild periodontitis, $10 \%$ had moderate periodontitis, and $4 \%$ had severe periodontitis. Table 2 explains about oral hygiene and periodontal status of participants among various age groups. Advancing age

Table 1: Sociodemographic, clinical, and other relevant characteristics of participants

\begin{tabular}{|c|c|c|c|}
\hline Variable & & $n$ & (\%) \\
\hline \multirow[t]{2}{*}{ Sex } & Male & 216 & 54 \\
\hline & Female & 184 & 46 \\
\hline \multirow[t]{3}{*}{ Age } & Less than 30 & 201 & 50.2 \\
\hline & $30-40$ & 87 & 21.8 \\
\hline & More than 40 & 112 & 28 \\
\hline \multirow[t]{2}{*}{ Marital status } & Single & 220 & 55 \\
\hline & Married & 169 & 42.3 \\
\hline \multirow[t]{4}{*}{ Education } & Primary & 35 & 8.8 \\
\hline & Intermediate & 38 & 9.5 \\
\hline & Secondary & 79 & 19.8 \\
\hline & University & 248 & 62 \\
\hline \multirow[t]{4}{*}{ Family income } & $<5,000$ & 64 & 16 \\
\hline & $5,000-10,000$ & 145 & 36.3 \\
\hline & $10,000-15,000$ & 85 & 21.3 \\
\hline & $>15,000$ & 106 & 26.5 \\
\hline \multirow[t]{2}{*}{ Smoking } & Yes & 126 & 31.5 \\
\hline & No & 274 & 68.5 \\
\hline \multirow[t]{2}{*}{ Medical problem } & Yes & 54 & 13.5 \\
\hline & No & 346 & 86.5 \\
\hline \multirow[t]{4}{*}{ Frequency of toothbrushing } & 0 & 79 & 19.8 \\
\hline & Once & 220 & 55 \\
\hline & More than once & 64 & 16 \\
\hline & 3 & 37 & 9.2 \\
\hline \multirow[t]{3}{*}{ Frequency of dental visit } & Regular & 112 & 28 \\
\hline & Irregular & 182 & 45.5 \\
\hline & For pain & 106 & 26.5 \\
\hline \multirow{2}{*}{$\begin{array}{l}\text { History of periodontal } \\
\text { treatment }\end{array}$} & Yes & 181 & 45.3 \\
\hline & No & 219 & 54.8 \\
\hline
\end{tabular}

showed increased severity and extent of periodontal diseases among the population.

\section{Impact of Periodontal Diseases on QoL}

Table 3 shows the distribution of responses to OHIP items for all subjects. Fairly often/very often was reported on one or more items of OHIP-14 by patients with gingivitis (11.38\%), mild periodontitis (17.61), moderate periodontitis (16.07\%), and about the same amount as of gingivitis of those with severe periodontitis (11.16\%). The mean OHIP-14 score is $13.92 \pm 8.21$. Physical pain and psychological disability were the most frequently reported complaints among the participants (Table 4). Only physical disability, psychological disability, and handicap subscales showed a significant difference in periodontal severity. The average OHIP-14 score failed to reach the level of significance among various periodontal severities.

In the present research, results showed higher or equal mean score among chronic gingivitis subjects compared to that of periodontal subjects.

Among patients with chronic gingivitis, subscales like physical disability, psychological disability, and handicap score showed significantly less values than that of mild periodontitis. And the average score of psychological disability subscale shows a statistically significant higher level among mild periodontitis compared to its moderate and severe counterparts. The average score on the handicap scale for patients with moderate periodontitis was significantly higher than that for patients with chronic gingivitis.

\section{Discussion}

The QoL has been progressively recognized as a valid, suitable, and substantial gauge that measures the service needed and intervention results in modern-day public health investigation and practice. Health-related QoL is the amalgamation of objective and subjective evaluations that are needed for gauging effectiveness, preventive strategies, and to measure efforts for preventing disabling chronic diseases. ${ }^{14,34}$ Patient's perspective assessment and evaluation have emerged as a substantial research area. ${ }^{35}$ This has led to conducting more and more research on the patient-centered oral health status, which provided effective evidence to develop and modify the health policies. ${ }^{14,36}$

This study encompasses 256 subjects with chronic gingivitis, 88 with mild chronic periodontitis, 40 with moderate chronic periodontitis, and 16 with severe chronic periodontitis. A validated OHIP-14 questionnaire was used to assess the impact of periodontal disease on QoL. It is the most reliable, sensitive even to minor changes, and has proven adequate cross-cultural consistency. ${ }^{19,23,37,38}$ And also this measuring tool has been used by most of the researches for gauging the antagonistic effect of oral conditions on comfort or well-being. ${ }^{11,14,39}$ The other efficient instrument to measure periodontal disease and QoL is the OHQoL-UK, which is parallel to that of OHIP-14. The OHQoL-UK measures both negative and positive aspects of the relationship

Table 2: Oral hygiene and periodontal status of participants by age

\begin{tabular}{|c|c|c|c|c|c|c|c|c|c|}
\hline \multirow[b]{2}{*}{ Variables } & \multicolumn{2}{|c|}{$<30$} & \multicolumn{2}{|c|}{$30-40$} & \multicolumn{2}{|c|}{$>40$} & \multicolumn{2}{|c|}{ Total } & \multirow[b]{2}{*}{$p$ value } \\
\hline & Mean & $S D$ & Mean & $S D$ & Mean & $S D$ & Mean & $S D$ & \\
\hline $\mathrm{PI}$ & 1.62 & 0.37 & 1.69 & 0.37 & 1.69 & 0.38 & 1.6589 & 0.37792 & 0.98 \\
\hline $\mathrm{Gl}$ & 1.76 & 0.34 & 1.81 & 0.31 & 1.81 & 0.33 & 1.787 & 0.3358 & 0.92 \\
\hline PPD & 2.16 & 0.22 & 2.41 & 0.37 & 2.67 & 0.38 & 2.3615 & 0.38168 & $0.001^{*}$ \\
\hline CAL & 1.87 & 0.48 & 2 & 0.45 & 2 & 0.58 & 1.941 & 0.50987 & 0.39 \\
\hline
\end{tabular}

One way ANOVA test, post hoc: Bonferroni

${ }^{*} p$ value $\leq 0.05$ was statistically significant 
Impact of Periodontal Disease on Oral Health-related Quality of Life

Table 3: Distribution of responses to individual OHIP items

\begin{tabular}{|c|c|c|c|c|c|c|c|c|c|c|c|}
\hline & & \multicolumn{2}{|c|}{ Never } & \multicolumn{2}{|c|}{ Hardly ever } & \multicolumn{2}{|c|}{ Occasionally } & \multicolumn{2}{|c|}{ Fairly often } & \multicolumn{2}{|c|}{ Very often } \\
\hline & & $N$ & (\%) & $N$ & (\%) & $N$ & (\%) & $N$ & (\%) & $N$ & (\%) \\
\hline \multirow[t]{2}{*}{ Functional limitation } & Trouble pronouncing words & 295 & 73.8 & 41 & 10.2 & 48 & 12 & 8 & 2 & 8 & 2 \\
\hline & Worsened sense of taste & 242 & 60.5 & 51 & 12.8 & 91 & 22.8 & 16 & 4 & 0 & 0 \\
\hline \multirow[t]{2}{*}{ Physical pain } & Painful aching & 143 & 35.8 & 125 & 31.3 & 59 & 14.8 & 49 & 12.3 & 24 & 6 \\
\hline & Uncomfortable to eat & 123 & 30.8 & 92 & 23 & 79 & 19.8 & 90 & 22.5 & 16 & 4 \\
\hline \multirow{2}{*}{$\begin{array}{l}\text { Psychological } \\
\text { discomfort }\end{array}$} & Self-conscious & 278 & 69.5 & 73 & 18.3 & 33 & 8.3 & 16 & 4 & 0 & 0 \\
\hline & Felt nervous & 158 & 39.5 & 35 & 8.8 & 110 & 27.5 & 73 & 18.3 & 24 & 6 \\
\hline \multirow[t]{2}{*}{ Physical disability } & Diet has been unsatisfactory & 266 & 66.5 & 62 & 15.5 & 32 & 8 & 32 & 8 & 8 & 2 \\
\hline & Interrupted meals & 150 & 37.5 & 89 & 22.3 & 113 & 28.2 & 32 & 8 & 16 & 4 \\
\hline \multirow[t]{2}{*}{ Psychological disability } & Difficult to relax & 150 & 37.5 & 81 & 20.3 & 113 & 28.2 & 40 & 10 & 16 & 4 \\
\hline & Embarrassment & 165 & 41.3 & 72 & 18 & 88 & 22 & 24 & 6 & 51 & 12.8 \\
\hline \multirow[t]{2}{*}{ Social disability } & Irritable with other people & 163 & 40.8 & 82 & 20.5 & 80 & 20 & 42 & 10.5 & 33 & 8.3 \\
\hline & Difficulty doing usual jobs & 197 & 49.3 & 114 & 28.5 & 40 & 10 & 23 & 5.8 & 17 & 4.3 \\
\hline \multirow[t]{2}{*}{ Handicap } & Less satisfaction & 247 & 61.8 & 47 & 11.8 & 49 & 12.3 & 16 & 4 & 41 & 10.3 \\
\hline & Unable to function & 242 & 60.5 & 78 & 19.5 & 56 & 14 & 24 & 6 & 0 & 0 \\
\hline
\end{tabular}

Table 4: Multivariate analysis of differences in OHIP-14 subscales by periodontal disease severity

\begin{tabular}{|c|c|c|c|c|c|c|c|c|c|}
\hline & \multicolumn{2}{|c|}{ Chronic gingivitis $(A)$} & \multicolumn{2}{|c|}{ Mild periodontitis (B) } & \multicolumn{2}{|c|}{ Moderate periodontitis (C) } & \multicolumn{2}{|c|}{ Severe periodontitis (D) } & \multirow{2}{*}{$\begin{array}{l}\text { Significant } \\
\text { pairs }\end{array}$} \\
\hline & Mean & $S D Z$ & Mean & $S D$ & Mean & $S D$ & Mean & $S D$ & \\
\hline $\begin{array}{l}\text { OHIP-1 (functional } \\
\text { limitation) }\end{array}$ & 1.555 & 0.92 & 1.67 & 1.005 & 1.695 & 0.885 & 1.405 & 0.84 & None \\
\hline OHIP-2 (physical pain) & 2.235 & 1.165 & 2.535 & 1.355 & 2.4 & 1.19 & 2.56 & 1.45 & None \\
\hline $\begin{array}{l}\text { OHIP-3 (psychological } \\
\text { discomfort) }\end{array}$ & 1.855 & 1.015 & 2.12 & 1.09 & 2.145 & 1.15 & 1.775 & 1.535 & None \\
\hline OHIP-4 (physical disability) & 1.8 & 1 & 2.1 & 1.24 & 2.12 & 1.22 & 1.825 & 1.185 & $A$ vs $B$ \\
\hline $\begin{array}{l}\text { OHIP-5 (psychological } \\
\text { disability) }\end{array}$ & 2.2 & 1.285 & 2.355 & 1.195 & 2.175 & 1.29 & 1.75 & 1.055 & $\begin{array}{l}A \text { vs } B, B \text { vs } \\
C, B \text { vs } D\end{array}$ \\
\hline OHIP-6 (social disability) & 2.13 & 1.64 & 2.27 & 1.2 & 2.12 & 1.315 & 1.775 & 1.195 & None \\
\hline OHIP-7 (handicap) & 1.655 & 1.025 & 2.095 & 1.205 & 1.92 & 1.285 & 1.465 & 0.905 & $\begin{array}{l}A \text { vs } B, A \\
\text { vs } C\end{array}$ \\
\hline OHIP-14 & 13.43 & 8.05 & 15.145 & 8.29 & 14.575 & 8.335 & 12.555 & 8.165 & None \\
\hline
\end{tabular}

OHIP-14, oral health impact profile-14

Adjusted for age, sex, years of education, medical illnesses, smoking status, and family income

between oral health and QoL, which is not essential for the present research. ${ }^{1,12,13}$ Hence, OHIP-14 was used in the present research to measure the impact of periodontal diseases on QoL among Saudi population. The mean OHIP-14 score in the present research (13.92) recommends a reasonably greater influence of the oral health status on QoL of subjects. This may be attributed to patient's dental disease status, which required their appearance in the first instance. A well-structured population-based survey can provide a clear picture than a hospital-based study. Parallel research in Shanghai population showed a high mean OHIP score (10.8) among subjects with oral mucosal illness. ${ }^{5,40}$ Some research among pregnant women and the elderly also showed high mean OHIP-14 score. ${ }^{5,22,41}$ The OHIP-14 measure was translated into Arabic language and presented to be valid and reliable.

The reliability (internal) and validity (discriminate) were pleasing for all subscales. Generally, chronic gingivitis and mild periodontal disease had an undesirable influence on QoL, but it did not show any statistical difference between disease progressions. This outcome is an antagonist to that stated by Ng and Leung. ${ }^{14}$ Mild impact of periodontal diseases on patient QoL was seen for physical disability and psychological disability and handicap domain. This is in agreement to the findings reported by various researches where they have stated that the impact of periodontal disease on physical and psychological disability domains and also using the OHQoL-UK measure. ${ }^{12-14,42}$

The influence of oral health on the QoL of the subjects in the present research was significant; $27 \%$ (108/400) denotes that their oral health status had a certain effect on their QoL in one or other supplementary ways (i.e., especially scores of "fairly often" or "very often" in OHIP-14 subscales). The QoL plays a major role in perusing an effective oral health status among the population. The oral health status is highly dependent on QoL as it gets altered the feeling (psychological disability) (by making the food taste bad), which causes physical disability (by disturbing meals). These findings invite attention to the fact that the periodontal conditions impact day-today life activities and subsequently the overall QoL also. ${ }^{14}$

The present research also states that that the severity of periodontal illness was not significantly related to functional limitation, physical pain, psychological discomfort, and social disability domains. In disparity, $\mathrm{Ng}$ and Leung ${ }^{14}$ and Araújo et al. ${ }^{39}$ in their respective studies reported that oral health had a substantial influence on functional limitation and other subscales.

When chronic gingivitis is compared with chronic periodontitis (includes all type of periodontitis), an increased effect on QoL was 
detected in the chronic periodontitis group among the majority of OHIP-14 domains. Subjects with mild periodontitis had maximum mean scores for majority of domains. This may be due to a small number of subjects included and measured among the severe periodontitis group and large groups were involved among chronic gingivitis and mild periodontitis groups. These findings are dissimilar and inconsistent with those of other researches ${ }^{1,43,44}$ where adequate samples were included in all subsections.

\section{Conclusion}

The periodontal illness had a definite destructive impact on QoL of the people, and this impact shows no less changes in the severity among the Saudi population, indicating no significant change observed in QoL among patients with mild gingivitis to that of severe periodontal destruction. These findings can significantly influence the development and modification of health policies and also for assessment, planning treatment of periodontitis, and subsequent assessment of periodontal care.

\section{References}

1. Al Habashneh R, Khader YS, Salameh S. Use of the Arabic version of oral health impact profile-14 to evaluate the impact of periodontal disease on oral health-related quality of life among Jordanian adults. J Oral Sci 2012;54(1):113-120.

2. Locker D. Concepts of oral health, disease and the quality of life. Measur Oral Health Qual Life 1997;11:24.

3. General USPHSOotS, Dental NIo, Research C. Oral health in America: a report of the Surgeon General: National Institute of Dental and Craniofacial Research; 2000.

4. John MT, Miglioretti DL, LeResche L, et al. German short forms of the oral health impact profile. Comm Dent Oral Epidemiol 2006;34(4):277-288.

5. Lawal FB, Taiwo JO, Arowojolu MO. How valid are the psychometric properties of the oral health impact profile-14 measure in adult dental patients in Ibadan, Nigeria? Ethiopian J Health Sci 2014;24(3): 235-242.

6. Streiner DL, Norman GR, Cairney J. Health measurement scales: a practical guide to their development and use. USA: Oxford University Press; 2015.

7. Herdman M, Fox-Rushby J, Badia X. A model of equivalence in the cultural adaptation of $\mathrm{HRQ}$ L instruments: The universalist approach. Qual Life Res 1998;7(4):323-335.

8. Cascaes AM, Peres KG, Peres MA. Periodontal disease is associated with poor self-rated oral health among brazilian adults. J Clin Periodontol 2009;36(1):25-33.

9. Cunha-Cruz J, Hujoel P, Kressin N. Oral health-related quality of life of periodontal patients. J Period Res 2007;42(2):169-176.

10. Ferreira Lopes MW, Santos Gusmao E, de Vasconcelos Alves R, et al. The impact of chronic periodontitis on quality of life in Brazilian subjects. Acta Stomatol Croat 2009;43(2):89-98.

11. Jowett AK, Orr MT, Rawlinson A, et al. Psychosocial impact of periodontal disease and its treatment with $24-\mathrm{h}$ root surface debridement. J Clin Periodont 2009;36(5):413-418.

12. López R, Baelum V. Oral health impact of periodontal diseases in adolescents. J Dent Res 2007;86(11):1105-1109.

13. Needleman I, McGrath C, Floyd P, et al. Impact of oral health on the life quality of periodontal patients. J Clini Periodont 2004;31(6):454-457.

14. Ng SK, Leung WK. Oral health-related quality of life and periodontal status. Commun Dent Oral Epidemiol 2006;34(2):114-122.

15. Patel RR, Richards PS, Inglehart MR. Periodontal health, quality of life, and smiling patterns-an exploration. J Periodontol 2008;79(2): 224-231.

16. Allen PF. Assessment of oral health related quality of life. Health Qual Life Outcomes 2003;1(1):40.

17. McGrath C, Bedi R. The value and use of 'quality of life' measures in the primary dental care setting. Prim Dent Care 1999;6(2):53-57.
18. Al Shamrany M. Oral health-related quality of life: a broader perspective. 2006;12(6):894-901.

19. Slade GD. Derivation and validation of a short-form oral health impact profile. Commun Dent Oral Epidemiol 1997;25(4):284-290.

20. Sanders AE, Slade GD, Lim S, et al. Impact of oral disease on quality of life in the US and Australian populations. Commun Dent Oral Epidemiol 2009;37(2):171-181.

21. Fernandes MJ, Ruta DA, Ogden GR, et al. Assessing oral health-related quality of life in general dental practice in Scotland: validation of the OHIP-14. Commun Dent Oral Epidemiol 2006;34(1):53-62.

22. Kotzer RD, Lawrence HP, Clovis JB, et al. Oral health-related quality of life in an aging canadian population. Health Qual Life Outcomes 2012;10(1):1.

23. Locker D, Jokovic A, Clarke M. Assessing the responsiveness of measures of oral health-related quality of life. Community Dent Oral Epidemiol 2004;32(1):10-18.

24. Slade G, Nuttall N, Sanders A, et al. Impacts of oral disorders in the United Kingdom and Australia. Br Dent J 2005;198(8):489.

25. Brislin RW. Back-translation for cross-cultural research. J Cross-cultural Psychol 1970;1(3):185-216.

26. Cronbach LJ. Coefficient alpha and the internal structure of tests. Psychometrika 1951;16(3):297-334.

27. Löe H, Silness J. Periodontal disease in pregnancy I. Prevalence and severity. Acta Odontolog Scandina 1963;21(6):533-551.

28. Silness J, Löe H. Periodontal disease in pregnancy II. Correlation between oral hygiene and periodontal condition. Acta Odontolog Scandina 1964;22(1):121-135.

29. Page RC, Eke PI. Case definitions for use in population-based surveillance of periodontitis. J Periodontol 2007;78(Suppl 7S): 1387-1399.

30. Eke PI, Page RC, Wei L, et al. Update of the case definitions for population-based surveillance of periodontitis. J Periodontol 2012;83(12):1449-1454.

31. Organization WH. Oral Health Surveys: Basic Methods. World Health Organization; 2013.

32. Armitage GC. Development of a classification system for periodontal diseases and conditions. Ann Periodont 1999;4(1):1-6.

33. Kaur J, Jacobs R, Huang Y, et al. Salivary biomarkers for oral cancer and pre-cancer screening: a review. Clin Oral Investig 2018. 1-8.

34. Hennessy $\mathrm{CH}$, Moriarty DG, Zack MM, et al. Measuring health-related quality of life for public health surveillance. Public Health Rep 1994;109(5):665.

35. Buck D, Newton JT. Non-clinical outcome measures in dentistry: publishing trends 1988-98. Commun Dent Oral Epidemiol:Comment 2001;29(1):2-8.

36. Birch S, Ismail A. Patient preferences and the measurement of utilities in the evaluation of dental technologies. J Dent Res 2002;81(7): 446-450.

37. Allen PF, McMillan AS, Locker D. An assessment of sensitivity to change of the oral health impact profile in a clinical trial. Commun Dent Oral Epidemiol 2001;29(3):175-182.

38. Allison $P$, Locker $D$, Jokovic $A$, et al. A cross-cultural study of oral health values. J Dent Res 1999;78(2):643-649.

39. da Silva Araújo AC, Gusmão ES, Batista JEM, et al. Impact of periodontal disease on quality of life. Quintessence Int 2010;41(6).

40. Liu L-J, Xiao W, He Q-B, et al. Generic and oral quality of life is affected by oral mucosal diseases. BMC Oral Health 2012;12(1):2.

41. de Oliveira BH, Nadanovsky P. Psychometric properties of the Brazilian version of the oral health impact profile-short form. Commun Dent Oral Epidemiol 2005;33(4):307-314.

42. Okunseri C, Chattopadhyay A, Lugo RI, et al. Pilot survey of oral healthrelated quality of life: a cross-sectional study of adults in Benin city, edo state, Nigeria. BMC Oral Health 2005;5(1):7.

43. Drumond-Santana T, Costa FO, Zenóbio EG, et al. Impact of periodontal disease on quality of life for dentate diabetics. Cad Saude Publica 2007;23(3):637-644.

44. Brennan D, Spencer A, Roberts-Thomson K. Quality of life and disability weights associated with periodontal disease. J Dent Res 2007;86(8):713-717. 